\title{
The Return of Education in Special Education: Phenomenology of Perception Inspiration
}

\author{
He Ping \\ Wuhan University of Technology \\ Emai:15977440@qq.com
}

\begin{abstract}
From Phenomenology of Perception, it include of images of people, epistemology and ethics,For person of disabilities analyze taught ability, cognitive process, different unfamiliar face,To outline the appearance of special education,And for today's disorder educational rights of ideological trend and Policy Orientation.To construction rationalization and justification of discussion, And look forward to construction the appearance of education, to rich disorder discussion on special education.
\end{abstract}

Keywords:Phenomenology of Perception, Special Education, person of disabilities

\section{Whose right to education has a priority}

In our country, special education has experienced a process from scratch, and in the process of strengthening implementation of special education, there will be some practical problems that plague teachers and education itself in specific special education, which deserves our re-positioning and reflection of development of special education itself. In a specific special education course, teachers and teacher assistants only deal with physiological and emotional problems of students with very serious mental retardation in the centralized special education classes, which takes up most of the time, resulting in impaired educational rights and interests of other students with mild to moderate retardation. In order to avoid the impact on right to education of others who are relatively able to learn, students with very heavy intelligence and multiple obstacles and emotional disorders should receive centralized management, to ensure that they still have learning ability, have the opportunity to education.

In the actual implementation level of special education, the three categories of students with very serious intelligence and multiple obstacles, mood disorders and autism are often complained by teachers and parents of other students as trouble makers due to their teaching needs and behavior patterns. To be sure, right to education of general healthy, normal students needs to be protected. However, can justice of one party justifiably become unfair challenge to the other party? In other words, can we deprive other groups' right to education to protect the right to education of a particular group? The so-called integration of education is not only to place students with different educational needs in a common teaching space, so that they affect each other; but to respect for right to education of children with different needs, so that children can recognize from childhood that, everyone has appearance, intelligence, temperament, advantages and reactions different from others. However, in the practical work, should we give priority to right to education of healthy, normal students or students with special demand? How to choose between the two, or should we take them into account at the same time? For educators, in the gradual deepened implementation of special education, this is an unavoidable problem.

\section{See the essential function of special education from the perspective of phenomenology of perception}

Phenomenology of perception argues that all human perceptual actions and all acts are intentional. Intentionality constructs context of relationship between people and the world, and thus further extends various relationships. Intentionality has a priori character, which intentionally points to the target before logical thinking of people and drives people towards this target. From another level, represented post-meaning of intentionality is: "I can". Even in the field of special education, those with extremely heavy intelligence and multiple obstacles who have the most questionable ability to learn, and must depend on others all the time to have the means to extend the life, still manifest significance of existence that "I can" in every aspect of their life. The manifestation of significance of existence can be explained in the example of feeding: When the spoon full of food is delivered to 
people with extremely heavy intelligence and multiple obstacles, he will naturally open the mouth and greet the food. We can reasoningly decompose the act of natural opening of mouth to greet the food into a number of subtle steps: visual organs (eyes) see food, visual nerve conducts to the brain, and then the brain orders the action nerve to open the mouth. Before the action that the visual organ looks to the physical space of the food, that is, before it "watches" the food, the person has been orientated towards the food. This action of "orientation" is intentionality defined in phenomenology. Intentionality not only refers to the temporal and spatial position of the object, but also manifests primodial ability of people and kinetic energy of the act. Through the intentionality- looking towards spatial position of food-- can "I can" be specifically manifested. It is because "I can" that people build a wide range of relationships with their living world. Education is based on the primodial ability as a starting point to show infinite possibilities with the priori and primodial intention. Thus, as Langeveld said: "If people do not have this primodial ability, then their existence is wasted." [1]

In addition, the existence of human beings cannot be separated from the body, and the body is always in intentional activities, manifesting ability at all times. Those with this primodial ability naturally have educability. In the field of special education research, educability which is rarely noticed and discussed obtains the basis of argument through ontological analysis of phenomenology of perception.

\subsection{Take breakthrough of self-border as education}

The body defined in phenomenology of perception is different from the "physical body", which is "the body in the context of the relationship", "the body in the living world", that is, "being in the world" as referred to in phenomenology. The body is like an anchor with which we can live in the vast world; ${ }^{[3]}$ the body is also the mechanism through which we can embrace the world. In perception and action of the body, we belong to the world, and also occupy the world. Take breath as an example, in the observation of phenomenology of perception, through the priori action of breath, alveolar is full of air that originally belongs to the world, and we therefore occupy a part of the world in the body: at the same time, because the body is in the world, it is owned by the world and surrounded by air as part of the world. Through the body, the world and people break away from the framework of mind-body dualism, constructing chaos ambiguous "third orientation" that belongs to each other, cannot be divided, and cannot clarify the separation of subject and object.

In this view, the cognitive behavior of those with extremely heavy intelligence and multiple obstacles is a process that gives meaning to the body as the orientation. In educational activities, students with very serious intelligence and multiple obstacles take their "body intention" as the orientation, and have the meaning of teaching materials, teaching aids, and even teaching content. Education is no longer a one-way behavior in which teachers wishfully provide textbooks to learners, and force the learners to fulfill educators' expectations. Education should be the process in which: educators return to the physical basis of students with very serious intelligence and multiple obstacles, respond to learners, serve as subjects together as the learners, commonly construct meaning and constantly break through boundaries of self.

\subsection{Fremdbeit}

In terms of epistemology, when we measure others with existing cognition, if others transcend boundaries of our cognition, fremdbeit will generate. Take children cognition as an example: in the beginning, children do not know function of items such as tambourine. The appearance of tambourine is strange, unfamiliar for him, that is, the item is beyond its cognitive boundaries. He is likely to bite the tambourine, grab it to play, or use it to knock his feet. Because this item has heterogeneous characteristics and is never experienced in the past, children will clearly identify presence of tambourine, and even intentionally move toward the tambourine, reaching out to touch or beat it. Once he sees his mother trying to beat the tambourine by hand, so that it issues sound unheard before, he is likely to follow suit and try to create a similar sound. Through such a cognitive process, tambourine becomes part of children's recognition of the world, and when he sees similar items, his first action may possibly be not biting it, but beating it. In this example, we can observe that fremdbeit is a challenge that challenges the boundaries of "my" cognition of the world.

From the epistemological point of view, "education serves as relationship demanding continuous construction", 
and highlighting education is a process of constantly breaking through self-border. It is because in the continuous construction of relationship with others, one's own life world can be constantly extended. As phenomenology of perception emphasizes: where I perceive, is where my living world exists; the boundary of my perception is also the boundary of my world. If we return to the existence level of people when we discuss education, universal significance and purpose of education will then reproduce. With the re-reduction of educational significance, all the discussions on the right to education, returning to mainstream, integration of education, educational content, etc., have place to return to.

\section{Conclusion}

Discussion of special education will ultimately return to the controversial issue of specialization of education. To get rid of specialization in special education, the main spirit is to prevent education from becoming a mechanism for class reengineering. However, it is educational institution that should be responsible for marginalization, labeling and stigma of those with physical and mental disabilities, or it is a result of our insufficient tolerance of "difference"? Perhaps, this is a topic worthy of further discussion. It is not difficult for special education to get rid of specialization, what is difficult is: how to make fremdbeit and difference tolerant by the diversification of society. It is because, even if special education gets rid of specialization, returns to the mainstream, in integration of education, educators can still cause marginalization, labeling and stigma of students with physical and mental disorders with the virtue of different educational methods or materials. What we need to think about is: legitimacy and necessarily of fremdbeit.

In the specific special education, some subjective thinking stereotypes continue to affect implementation effect of policies and regulations. For domestic special education with nearly a thousand years of development, discussion of relevant anthropology, epistemology and ethics should help clarify significance, mission, connotation, model, field, teacher-student relationship of special education, or even core issue like obligation and reality of compromise of special education, and thus contribute to return of education in special education. Education for those physically and mentally handicapped should have the same purpose as all others. It should be not only the process of unilateral teaching of learners, but also a dialogue between both sides, and a dynamic process wandering between the two extremes of self-realization and social integration. The core purpose of special education is to: through education methods, support and help self-realization of the disabled in the group.

\section{References:}

[1]Rui Shen, Research on the Legislation of Anti-domestic Violence in China, Anhui University(2016)

[2]Yilan Xia, An Analysis of the Party in the Concept of Domestic Violence,Collection of Women's Studies (2014)

[3]Xiaoqin Xie, Xiaoding Wang, A Study of Reasons of Women Inflicting on Domestic Violence, Review of Literature and History (2001)

[4]Liming Wang, Some Questions in the Amendment of Marriage Law, Law Science (2001)

[5]Yinlan Xia, The Law on Prevention and Punishment of Domestic Violence -With Focus on Institutional Constriction, Beijing: China Social Sciences Press (2011) 